\title{
ASPECTOS DA SAÚdE DA CRIANÇA E ENFERMAGEM*
}

\author{
** Haydée Guanais Dourado
}

RBEn/02

DOURADO, H. G. - Aspectos da saúde da criança e enfermagem. Rev. Bras. Enf.; DF, $33: 9-21,1980$.

Por resolução de 21-12-1976 a Assembléia Geral das Nações Unidas aprovou a respeito do Ano Internacional da Criança, entre outros itens, o seguinte: Ajuda aos grupos ameaçados e mais prejudicados, objetivando o desenvolvimento social e econômico dos países. Nossa proposição, neste trabalho, visa contribuir para que os membros do XXXI Congresso Brasileiro de Enfermagem se importem mais com a criança e lhe dêem ajuda profissional e fraterna, neste país em que há alarmante número de crianças ameaçadas e prejudicadas.

\section{1 - SOCIEDADE BRASILEIRA}

A familia, a igreja, a escola, o emprego e centenas de outras instituições de que se valem as pessoas formam-lhes uma teia de vida, de tal modo que elas podem crescer e se tornar adultos sadios e ocupados, aceitando o desáfio de viver.
Acontece assim com a totalidade dos brasileiros? Certamente não acontece. Façamos uma análise ampla. Em que meio cresce a maioria das crianças? O economista Carlos Langoni, na Fundação Getúlio Vargas, divide a população do país em quatro grupos sócioeconômicos, que são: a classe urbana inferior, o proletariado rural, a nova classe média e a nova classe superior; afirma esse pesquisador que cerca de $80 \%$ da população está entre os dois primeiros grupos.

E certo que entre familias de operários e de homens da lavoura e pecuária, algumas se classificam razoavelmente bem, quanto à qualidade de vida. Entretanto muitos são pobres demais, grande é a preocupação dos que nos governam porque a distribuição dos bens e rendimentos está viciada e muito desigual. Dados reais apontam $50 \%$ da população como não tendo o suficiente para viver.

* Conferência proferida no XXXI CBEn - Fortaleza - Ceará - 1979.

* Enfermeira, Professora Titular da Escola de Enfermagem Ana Néri, Universidade Federal do Rio de Janeiro. 
DOURADO, H. G. - Aspectos da saúde da criança e enfermagem. Rev. Bras. Enf.; DF, $33: 9-21,1980$.

Então transparece esta triste situação na dificuldade Ju impossibilidade para muitos de atingir:

1. Esclarecimento sobre realidades espirituais;

2. Vida em família para que possam, nesse grupo social e em outros, ao realizarem suas ações, desde as infantis, com criatividade, ter quem utilize suas ações;

3. Saúde, educação escolar, habitação sadia e trabalho. que é de sua natureza de pessoa humana, vivendo no mundo que encontrou, mas que está comprometida com a obra do mundo, que é contínua.

Numa interação inseparável com a baixa renda desses $50 \%$ da população existem os fenômenos com os quais têm que lidar os profissionais de saúde, no trato com o grupo materno-infantil.

\section{2 - PROBLEMAS LIGADOS A SAÚdE DA POPULAÇAO POBRE}

Doenças evitáveis, falta das condições acima citadas, falta de terra para o agricultor e criador estão entre as ocorrências comuns nesse setor da população que tem desvantagem econômico-social.

E grande o sofrimento humano, em nosso país, dos que migram sem resolver seus problemas básicos acima referidos, dos que se despedem de filhos que morrem por falta de alimento e assistência, dos que se vêem injustamente despojados de suas propriedades, como conseqüência de, na sua vida abaixo do nível jurídico, não as terem registrado, dos que não se sentem seguros, dos que não têm habitação, da mão-de-obra na nova vida urbana.

Examinemos dados, parte dos quais são do crescimento vegetativo e parte são das migrações rurais e urbanas: em 1960 tínhamos $45 \%$ de população urbana, em 1970, 50\%; em 1979, $63 \%$.

\section{3 - GRUPO MATERNO-INFANTIL E SUA SAÚDE}

O grupo materno-infantil representou em $1977,70,98 \%$ da população brasileira.

Tabela 1 - BRASIL - POPULAÇÃO MATERNO-INFANTIL - 1977

\begin{tabular}{|c|c|c|}
\hline GRUPO ETARIO & NOMERO & 8 \\
\hline 0 - 4 anos. & I7.409.669 & I5, 438 \\
\hline 5 - 9 anos & $I 4.870 .994$ & $13,18:$ \\
\hline I0 - I4 anos & I 4.092 .467 & 12,49 \% \\
\hline I5 - I9 anos -população masc. & 6.205 .650 & $5,50 \%$ \\
\hline I5 - 49 anos.-população fem. & $27.4 I 7.690$ & 24,308 \\
\hline TOTAL DO GRUPO MATERNO INFANTIL & 80.086 .734 & $70,98 \%$ \\
\hline
\end{tabular}

FONTE: Ministério da Saúde.

NOTA: Os percentuais foram calculados sobre sobre a população total do Brasill, 112.830 .000 para 1977 (arredondados). 
DOURADO, H. G. - Aspectos da saúde da criança e enfermagem. Rev. Bras. Enf.; DF, $33: 9-21,1980$.

Segundo o Ministério da Saúde, em descrição resumida, o grupo materno infantil, acima referido, caracteriza-se por: elevadas taxas de mortalidade e morbidade; elevada proporção de óbitos de menores de 5 anos em relação ao total de óbitos; e predominância de óbitos por causas evitáveis. As tabelas 2,3 e 4 mostram alguns desses aspectos da saúde da criança.

Tabela 2 - EVOLUÇA DAS TAXAS DE MORTALIDADE INFANTIL NAS CAPITAIS BRASILEIRAS NOS ANOS 1950, 1960 e 1970.

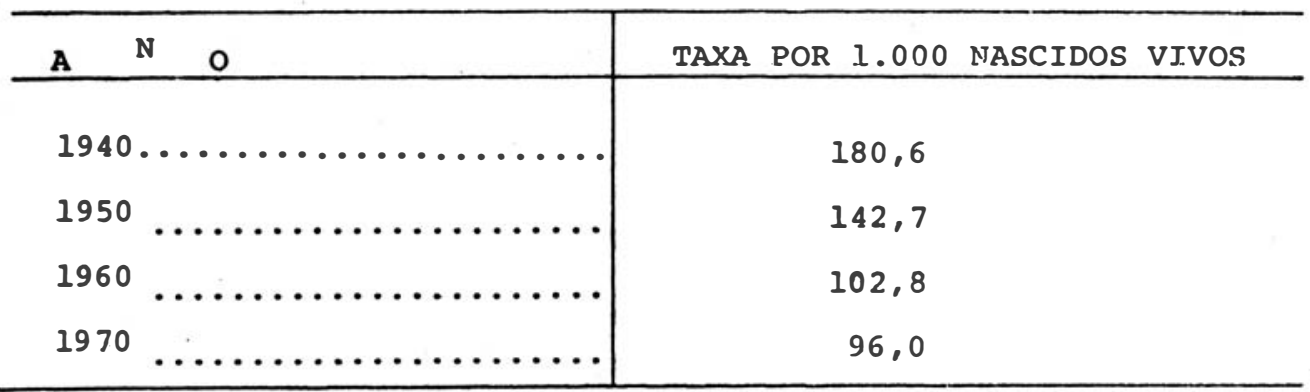

FONTE: Ministério da Saúde.

Na Tabela 2 são altíssimas as taxas e a Tabela 3 mostra a realidade grave nas capitais da Grande Região Nordes- te; esta área é responsável pela média nacional alta.

Tabela 3 MORTALIDADE GERAL E INFANTIL NA GRANDE REGIAO NORDESTE-MUNICIPIOS DAS CAPITAIS - 1976

\begin{tabular}{l|c|c}
\hline MUNICÍPIOS & $\begin{array}{c}\text { MORTALIDADE GERAL } \\
(\mathrm{p} / 1.000 \mathrm{hab} .)\end{array}$ & $\begin{array}{c}\text { MORTALIDADE INFANTIL } \\
(\mathrm{p} / 1.000 \mathrm{~N} . \mathrm{V} .) \text { (a) }\end{array}$ \\
\hline TOTAL & 10,9 & 92,6 \\
São Luis & 8,4 & 65,2 \\
Teresina & 8,6 & 76,6 \\
Fortaleza & 8,6 & 76,2 \\
Natal & 10,1 & 84,7 \\
João Pessoa & 13,8 & 117,0 \\
Recife & 12,5 & 105,1 \\
Macéio & 16,9 & 154,5 \\
Aracajú & 11,9 & 108,3 \\
Salvador & 10,5 & 86,9 \\
Vila dos Remédj.os & 42 & 83,3 \\
\hline
\end{tabular}

FONTE: CRESNE, FSESP do Ministério da Saúde.

(a): Calculado com base nos Nascidos Vivos esperados. 
DOURADO, H. G. - Aspectós da saúde da criança e enfermagem. Rev. Bras. Enf.; DF, $33: 9-21,1980$.

A Tabela 4 mostra a desnutrição agravando a mortalidade na maioria dos casos, em menores de 5 anos.

Tabela 4 - DEFICIENCIA NUTRICIONAL COM CAUSA DE MORTES ENTRE MENORES DE 5 ANOS DE IDADE EM TRES CIDADES - 1973

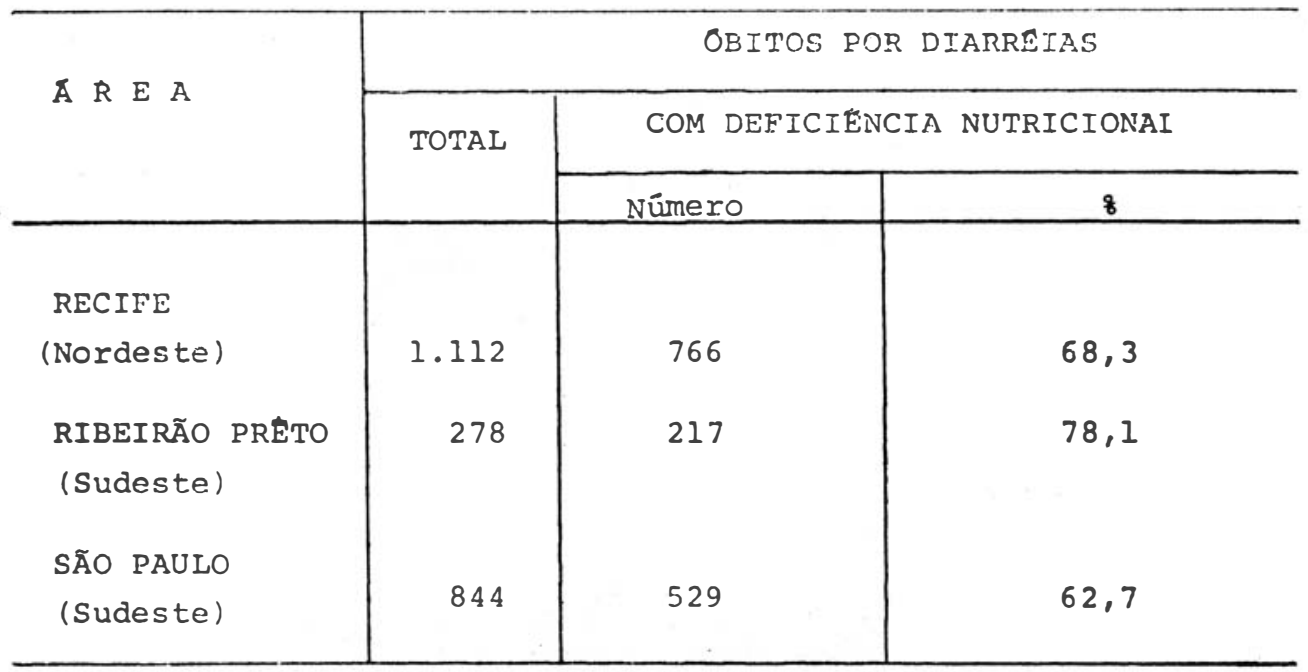

FONTE: Organização Panamericana da Saúde (OPAS)/Organização Mundial de Saúde Investigação Interamericana de Mortalidade na Infância - 1973.

Uma vez que a maioria da população brasileira está no grupo materno infantil e que a assistência a tal grupo é prioritária, vejamos agora dados das enfermeiras e sua profissão. Deles e dos demais compreendidos nos serviços de saúde dependerá, em grande medida, a assistência ao grupo materno infantil.

4. ENFERMAGEM: SUBSISTEMA COM SEU COMPLEXO DE INSTITUIÇOES

\subsection{Aparelho formador.}

4.1.1. Instituiçōes para os profissionais de $3 .^{\circ}$ grau.

Em 1923 foi aberto no Brasil a primeira escola de enfermagem (Escola Ana Néri) com modelo dos Estados Unidos que assimilaram a de Florence Nightingale da Grã-Bretanha acrescentando-lhe características de sua cultura.

De 1925 até o presente tem diplomado enfermeiras, tem se automelho- rado, e emprestado colaboração para difusão do modelo no país, inclusive na Congregação de São Vivente de Paulo e outras importantes Congregações que participam da enfermagem em todo o território nacional. Em 1925, o modelo novo começou a influenciar a formação de enfermeiras obstétricas, tendo finalmente os dois cursos se integrado, por força da reforma universitária (Lei n. ${ }^{\circ}$ 5.540 de 1968). No começo dos anos 40 começou a formação de enfermeiras na Universidade de São Paulo, na capital; mutuamente esta escola e a original fortaleceram-se. As resistências de outros grupos ao modelo transformaramse aos poucos em assimilação desse novo ordenamento institucional; este último foi formalizado pela Lei n. ${ }^{\circ} \mathbf{7 7 5}$, de 1949. A seguir, depois da Lel de Diretrizes e Bases da Educação Nacional (1961) e de outras normas legais do ensino superior que caracterizaram a 
DOURADO, H. G. - Aspectos da saúde da criança e enfermagem. Rev. Bras. Ene.; DF, $33: 9-21,1980$.

Reforma Universitária (anos 60 e 70), a formação de enfermeiros se situou entre as congêneres da área da saúde. Finalmente, a partir de 1972 , existem cursos de mestrado em funcionamento regular.

Dos cursos de mestrado estão surgindo de modo encorajador pesquisas de enfermagem. A pesquisa deverá ser um dos elementos mais poderosos não só para ajustar a prestação de serviços e a educação de enfermagem a seus fins verdadeiros como também para o aprofundamento e criatividade da enfermagem, contribuindo não só para ela se tornar melhor como para dar maior segurança e esperança aos que a exercem.

\subsubsection{Comissão de Especialistas}

Em 1979 o Ministério de Educação e Cultura - SESU - passou a contar com a Comissão de Especialistas do Ensino de Enfermagem, que deverá contribuir para adequar o aparelho formador dos profissionais de nível superior às necessidades do país. Comissōes anteriores funcionaram em 1962, de 1964 a 1966 e em 1975; foram útels ao país.

\subsubsection{Instituições do $2 .^{\circ}$ grau}

Desde a Lei n. $775 / 1949$, continuada pela Leil n. $5.692 / 1971$, processa-se a formação de auxiliares de enfermagem. Desde a Lei n. 4.024/1961, continuada pela Lei n. ${ }^{\circ} 5.692 / 1971$ desenvolve-se a formação de técnicos de enfermagem.

o ordenamento institucional se processa: foram assimiladas as antigas ocupações de prático de enfermagem e de categorias militares; há articulação entre o curso de auxiliar de enfermagem e o de técnico de enfermagem, uma vez que o candidato, tendo completado o curso de auxiliar de enfermagem pode se diplomar como técnico mediante aproveitamento de estudos. Há, também flexibilidade para se utilizar a via regular e a supletiva. Utiliza-se o curso emergencial (sem o $2 .^{\circ}$ grau) para auxiliar de enfermagem, para atender a áreas mais pobres.

\subsubsection{Outro pessoal auxiliar}

A maioria das pessoas que trabalham sob a coordenação de enfermeiros é constituída de atendentes, que, entretanto não dispõem de instituiçōes ágeis para os adequar às necessidades do país em mudança. O grupo de atendentes de enfermagem requer a ajuda de várias medidas legals e administrativas para ter acesso às ocupaçōes de enfermagem mais adiantadas. Seria funcional criar-se uma providência administrativa em cada serviço de saúde com a finalidade de os fazer ingressar nos cursos regulares do aparelho formador, sem perderem seus salários; utilizando seu trabalho durante os estágios do curso, as despesas seriam, em parte, compensadas.

Do mesmo modo deveriam ser tratados os visitadores sanitários, as parteiras práticas e, ainda, o pessoal subsidiário para o tratamento a domicilio de crianças convalescentes, crônicos e geriátricos, no caso de satisfazerem os requisitos para ingresso nos cursos regulares.

Haverá outros no futuro? Não se pode responder: a interdisciplinaridade, no trabalho, não prescinde da identidade no seu grupo de profissão. Parece-nos importante, em todos os nivels, a identidade ocupacional com hierarquias definidas.

\subsection{Orgãos de classe}

\subsubsection{A Associaçāo Brasileira de Enfermagem e seus asso- ciados}

A ABEn tem servido aos enfermeiros desde 1926; desde 1971 acolhe enfer- 
DOURADO, H. G. - Aspectos da saúde da criança e enfermagem. Rev. Bras. En?.; DF, $33: 9-21,1980$.

meiros e técnicos de enfermagem. Representa um papel ímpar na enfermagem: é o grupo coeso que está em ação conjugada, apesar de estar seus membros em área física de dimensão continental. A ABEn preenche seus fins estatutários de órgão cultural. Ademais, tem prestado serviços ao país, quer quanto à educação formal, estudos curriculares, pesquisa e outros, quer quanto ao exercício profissional, suprindo assessoria e diretrizes para criação de cargos e empregos. Tem guiado interações e interpretado dados sociológicos de enfermagem.

\subsubsection{Outras associações}

Os Sindicatos e a União Nacional dos Auxiliares e Técnicos de Enfermagem têm tido participação no complexo institucional de enfermagem. Os sindicatos mais antigos prestam auxílio de acordo com seus fins.

A antiga UNAE trabalhou e obteve um bom acerto institucional representado pelo Decreto-Lei n. ${ }^{\circ}$ 299/1967 que pôs na categoria de auxiliar de enfermagem os práticos de enfermagem (inclusive enfermeiros práticos antigos), além de outros, já equiparados aos auxiliares de enfermagem pela Lei n. ${ }^{\circ}$ 2.604/1955.

\subsection{A prática}

\subsubsection{A utilização dos serviços}

O público utiliza os serviços de enfermagem não só nos estabelecimentos da saúde organizada-hospitalares, parahospitalares, oficiais de saúde pública inclusive enfermagem escolar e do trabalho, como nos domicílios.

Estão ocorrendo mudanças sociais numerosas na utilização dos serviços. O Programa de Interiorização das Ações de Saúde e Saneamento, o Programa Nacional de Saúde Mental, o de Pneu- mologia e outros são exemplos de ajustamentos recentes da atenção à saúde da população.

O maior desafio que se tem anteposto à classe de enfermeiros, no país, parece-nos ser a prática profissional do presente. Requer talvez maior criatividade e maior interesse pelo outro, do que a prática nos hospitais. Requer pesquisa, planejamento e participação correta na assistência multiprofissional à saúde.

$\mathrm{Na}$ área de prestação de serviços a classe deverá estar ativa para preencher o espaço que puder encontrar, na busca de oportunidade de dar assistência de saúde ao povo. Educação e saúde para quase todos os brasileiros são as diretrizes novas.

Há muito o que providenciar nas 26 Unidades da Federação. Requer criação de programas de saúde mais numerosos e intercomunicação ágil com o aparelho formador. $\mathrm{Na}$ área da prática, mais do que na do ensino, os direitos constitucionais de todos nem sempre são assegurados para grupos minotórios (da mulher nas profissões, dos trabalhadores de apoio a enfermagem, por exemplo). Devemos lutar por melhores condições econômicas e outros direitos.

\subsubsection{Os Conselhos Federal e Regio- nais de Enfermagem}

Desde 1975 estão se desenvolvendo em todo o país os Conselhos Federal e Regionais de Enfermagem. São a rede para o controle dos aspectos legais do exercício dos enfermeiros e demais comprendidos nos serviços de enfermagem. O Código de Deontologia de Enfermagem, de 29 de março de 1976, e as resoluções pertinentes a muitos aspectos da vida do trabalho emanadas pelos Conselhos, juntamente com as demais normas legais em vigor são instrumentos para sua ação. Deve-se ao Conselho Federal de Enfermagem - com o qual colaborou a Associação Brasileira de 
DOURADO, H. G. - Aspectos da saúde da criança e enfermagem. Rev. Bras. Enf.; DF, $33: 9-21,1980$.

Enfermagem o estudo do anteprojeto de lei atualizado para o exercício da enfermagem. Quando for convertido em lei um passo importante terá sido dado para aperfeiçoamento das instituiçōes desse ramo no país.

\section{PESSOAL DE ENFERMAGEM COM TITULO REGISTRADO PARA EXERCICIO}

Finalmente a Tabela 5 dá informações atuais que são de interesse. Provém do registro central do Conselho Federal de Enfermagem. Como se sabe, os que trabalham no Serviço de Enfermagem têm que portar documento de inscrição (ou franquia provisória) do Conselho Regional de Enfermagem de seu Estado, fornecido após registro de seu título no Conselho Federal. A Tabela 7 mostra os dados recentes para o país do Conselho Federal de Enfermagem.

Quanto a enfermeiros e obstetrizes supõe-se que o número esteja próximo dos existentes; os demais deverão comparecer para inscrição, à medida que tomam conhecimento da sua obrigatoriedade legal; neste particular, a UNATE tem colaborado ativamente divulgando entre seus associados a necessidade da inscrição no COREN.

Tabela 5 - ENFERMEIROS E DEMAIS PESSOAL DE ENFERMAGEM COM REGISTRO NO CONSELHO FEDERAL DE ENFERMAGEM — 26/6/1979

\begin{tabular}{c|c|c}
\hline QUADROS E PESSOAL DE ENFERMAGEM & NOMEROS ABSOLUTOS & 8 \\
\hline $\begin{array}{c}\text { QUADRO I } \\
\text { Enfermeiros (I) }\end{array}$ & 18.334 & 26 \\
QUADRO II & & 7 \\
Técnicos de Enfermagem & 4.760 & \\
QUADRO III & & 67 \\
$\begin{array}{l}\text { Auxiliares de Enfermagem e } \\
\text { Parteiras prāticas }\end{array}$ & 47.506 & 100 \\
Total dos Quadros I, II e III & 70.600 & \\
\hline
\end{tabular}

FONTE: Conselho Federal de Enfermagem.

(1) Enfermeiros, inclusive obstetrizes que até 1963 eram diplomadas em cursos sob o controle de departamentos das escolas de medicina.

Esta Tabela 5 inclui o registrio não só dos graus dos enfermeiros, diplomas dos técnicos de enfermagem e certificados dos auxiliares de enfermagem e parteiras práticas (do Quadro III) como também de franquias provisórias de pessoas destas três categorias cujo títu- lo está em processo de registro prévio, quanto à sua vida escolar.

Além dos referidos, dos três Quadros, há os provisionados que são: atendentes de enfermagem (49.996), visitadores sanitárics (452) e instrumentadores em cirurgia (364) num total de 50.812 pro- 
DOURADO, H. G. - Aspectos da saúde da criança e enfermagem. Rev. Bras. Enf; DF, $33: 9-21,1980$.

visionados. No pais este total representa talvez a metade do seu número real existente. $O$ provisionamento deste pessoal se iniciou em 1975, seguindo até 1978, quando foi interrompido. Aguardam-se novas resoluçōes do Conselho Federal de Enfermagem, que, por sua vez, está tomando as providências cabíveis.

\subsection{Pessoal de enfermagem nos serviços}

Está faltando pesquisa e estatisticas acuradas para se conhecer a distribuição nos serviços do pessoal de enfermagem. Uma sugestão que poderia ajudar a todos: o COREN de cada Estado cooperar com a Fundação IBGE, anualmente, sendo-lhe permitida a leitura dos formulários preenchidos durante a Campanha Estatística dos Estabelecimentos Hospitalares e Para-Hospitala- res e Serviços Oficiais de Saúde Pública, no intuito de apontar possíveis incorreçōes para serem sanadas nas fontes das informaçōes, isto é, nos estabelecimentos de saúde.

Os Conselhos Federal e Regionais de Enfermagem possuem dados totais acurados; falta-lhes conhecer a distribuição, nos diferentes serviços de saúde, das diferentes categorias de pessoal de enfermagem.

\subsection{Estatisticas oficiais de 1973 e 1974}

O Anuário Estatístico do Brasil da Fundação IBGE dos anos de 1977 e 1978 publica, em diferentes tabelas, os dados do pessoal de enfermagem, em totais nacionais, dos estabelecimentos hospitalares e para-hospitalares e serviços oficiais de saúde pública, referentes a 1973 e 1974 . Consideradas $100 \%$ todas as categorias de pessoal de enfermagem, as percentagens de cada uma são:

Empregos ocupados por:

Em 1973

$\%$
Em 1974

$\%$
Enfermeiros

6,9

Técnicos de Enfermagem

Auxiliares de Enfermagem

Y'isitadores Sanitários

Parteiras práticas

Atendentes

$\begin{array}{rr}6,9 & 6,5 \\ \ldots & \ldots \\ -26,3 & 26,1 \\ 1,9 & 1,9 \\ 0,9 & 1,5 \\ 64,0 & 64,0\end{array}$

todos os escalōes. A distorção referida estará dificultando o trabalho de cada um.

Os enfermeiros dos serviços provavelmente terāo que tomar medidas novas e se intercomunicar: faltam-lhes outros. recursos, também. Sabe-se que têm aspiraçāo de conseguir organização administrativa para desempenhar ensino e supervisão de modo mais eficaz do que no presente, uma vez que desejam dar a seu trabalho uma atmosfera de desafio e criatividade, diminulndo is 
Dourado, H. G. - Aspectos da saúde da criança e enfermagem. Rev. Bras. Ene.; DF, $33 \cdot 9.9 .1$. 1980

inadequações. $\mathrm{t}$ que tem sido registrado repetidamente em recomendações dos Congressos Brasileiros de Enfermagem.

5.3. Utilização de recursos humanos de enfermagen: escassez de profissionais $e$ outros aspectos

O número de enfermeiros e técnicos de enfermagem vai aumentar: de 1976 em diante, programas do Governo Federal têm feito crescer em cerca de $60 \%$ o número de cursos universitários para a graduação de enfermeiros, bem como expandir as matrículas iniciais dos existentes. Os cursos de técnicos de enfermagem são dentre as três categorias os que mais crescem numericamente nos anos recentes .Os auxi- liares de enfermagem não só aumentam em número, como também muitos deles tornam-se técnicos de enfermagem. Também os atendentes têm acesso aos exames de suplência, a fim de se tornarem auxiliares ou técnicos em enfermagem.

Entretanto, é muito baixo o número de todo o pessoal de enfermagem com curso de formação.

Como mais uma evidência, a Tabela 6 mostra, quanto a empregos ocupados, a situação dos enfermeiros, confrontados com os de médicos, revelando possivel insuficiência de enfermeiros para os serviços. O número de nutricionistas está baixo; é mostrado para comparação apenas; sua profissão surgiu cerca de 20 anos após a de enfermagem.

Tabela 6 - EMPREGOS OCUPADOS POR MÉDICOS, ENFERMEIROS E NUTRICIONISTAS NOS ESTABELECIMENTOS DE SAÚDE - 1974

\section{ESTABELECIMENTOS DE SAUDE}

\begin{tabular}{lrrrrr}
\cline { 3 - 5 } PROFISSIONAIS & Hospitalar & Ambulatorial & $\begin{array}{c}\text { Oficiais } \\
\text { de Saúde } \\
\text { Pública }\end{array}$ & \multicolumn{2}{c}{$\begin{array}{c}\text { TOTAL } \\
\text { N.0 }\end{array}$} \\
\hline Médicos & & & & & \% \\
Enfermeiros & 62.743 & 23.516 & 9.762 & 96.021 & 89 \\
Nutricionistas & 8.508 & 1.167 & 897 & 10.572 & 10 \\
$\quad$ TOTAL & 1.441 & 81 & & 1.522 & 1 \\
& & & & 108.115 & 100 \\
\hline
\end{tabular}

FONTE: Dados do Ministério da Saúde citado no Anuário Estatístico do Brasil, 1978.

Erande o desafio que os dados do Anuário Estatístico do Brasil apontam. Levantamos, aqui, duas hipóteses: se os atendentes $(64 \%)$ trabalham sem a presença de enfermeiros fica em perigo a saúde e a vida dos que são assistidos; se trabalham juntamente com os enfermeiros estes terão de gastar grande parte de seu tempo em distribuição criteriosa de serviço, orientação e supervisão; de forma tal que pouco tempo e energia lhes restam para seus papéis técnicos. Este último aspecto seria agravado com os conflitos e tensões envolvidas, por falta de preparo dos atendentes para suas responsabilidades. Existem pois os desafios. Os enfermeiros dos serviços necessitam se preparar em cursos de educação continuada, de especialização e de mestrado, a fim de descobrirem, 
DOURADO, H. G. - Aspectos da saúde da criança e enfermagem. Rev. Biras. Enf.; DF, $33: 9-21,1980$.

por pesquisa, como renovar e melhorar seu trabalho. Fazemos nesta oportunidade a reflexão crítica de que devemos generalizar a metodologia científica mais do que o temos feito, para nos estimularmos com dados estatísticos e conhecimento da realidade; nosso alvo geral seria realizarmos terapia de enfermagem, prevenção de doenças e de incapacidades e promoção da saúde.

5.3.1. Reflexos do status da mulher: falhas nas hierarquias $e$ nas representações e escassez de empregos

O Conselho Internacional de Enfermeiras - ICN - em 1973 recomendou aos enfermeiros dos países membros que procurassem se preparar e galgar niveis a fim de participarem dos grupos que planejam e programam a assistência à saúde, bem como a educação, em todos os níveis, que interessa à prestação de assistência de enfermagem. Até certo ponto tem havido participação de enfermeiros em tal planejamento. Está evidente, entretanto, que ela não tem sido suficiente para as necessidades do país. A própria língua mostra que a enfermagem não está com o campo próprio que já é seu de fato - descrito como de enfermagem, Raras vezes utiliza-se a expressão certa "assistência à saúde". Há interação nos dois sentidos, a língua $\mathrm{e}$ as instituições $\mathbf{X}$ as instituições $\mathrm{e}$ a língua, de modo que não têm os enfermeiros a ajuda sociológica da língua, as estruturas jurídicas, a infraestrutura material e de pessoal para que possam prestar em alto nivel a assistência de enfermagem. Exemplos destas deficiências: saúde escolar, do trabalho, todos os órgãos maiores do INAMPS. Por que tais sinais de demora ou retardo na cultura? Os enfermeiros estão atrasados em muitas providências que deverão tomar.

Para mencionar apenas um fato: a profissão é de maioria feminina: há
94,3\% de pessoas deste sexo entre os graduados em 1977, segundo estatística da ABEn. Sofremos conseqüências da demora cultural, em nossas sociedades latino-americanas, presentes quanto aos direitos da mulher.

Em razão de planejamento e estruturas de pessoal para os serviços de enfermagem serem decididos quase sempre sem a participação de enfermeiros, o país continua vinte anos (1957, ano dos relatórios do levantamento de Recursos e Necessidades de Enfermagem até o presente) com a proporção de atendentes alta demais nos serviços. Cabem portanto, normas novas capazes de os atendentes ascenderem, por meio de cursos, a novos empregos e a níveis mais altos de trabalho e salário. O Governo Federal preocupa-se com as dificeis condições sociais do povo. Nós enfermeiros, devemos estudar medidas juntamente com representantes desses auxiliares mais simples dos nossos serviços, com o propósito de democratizar políticas de saúde e de fazer desaparecer alguns impedimentos da boa assistência à saúde. Programas aprovados de organização do ensino, em turmas, em locais próximos aos hospitais, talvez por iniciativa das associações, sindicatos ou cooperativas para este fim, talvez fossem medidas aconselháveis.

\section{SAÚDE E EDUCAÇAO: ASPECTOS DA SOCIEDADE}

\subsection{Instituições da sociedade civil}

Na França, o recente relatório para o Presidente Giscard D'Estaing do Inspetor de Finanças de Paris, Simon Nora, com seu grupo de técnicos, declara o seguinte: A reflexão sobre a informática e a sociedade reforça a conviç̧ão de que o equilíbrio das civilizações modernas repousa sobre uma alquimia difícil: a dosagem entre o exercício cada vez mais rigoroso de poderes privilegian- 
LUUkAnU, H. G. - Aspectos da saude da crıança e entermagem. Kev. Bras. Enr.; LF', $33: 9-21,1980$.

tes do Estado e uma exuberância crescente da sociedade civil.

A informática será o maior ingrediente desta dosagem.

E ainda: a "revolução informática" terá conseqüências muito mais abrangentes do que a "revolução tecnológica".

O comentário que consultamos é d? Professor Irineu Strenger, para o jornal "Estado de São Paulo", 31-7-1979, p. 21.

Há referência a computadores, pequenos, possantes e de baixo custo. Prevê-se sua imbricação, um setor com outro, e com os aparelhos de telecomunicação, toda uma rede de telemática, como denomina essa junção.

Contém o relatório a generalização de que a França utilizará informaçōe: da telemática assim como hoje utiliza a eletricidade, isto é, afetando toda a sociedade, influenciando a cultura inteira.

Estas reflexões são cabíveis. Está a sociedade brasileira que tem acesso a informações verdadeiramente perplexa com o problema do menor, suas carências, suas manifestações de desajustamento.

O novo plano nacional de desenvolvimento - III PND - inclui diretrizes sobre o trabalho e a educação para c menor, denotando tal preocupaçã.o. Também a Constituição, por meio da Emenda Constitucional n. ${ }^{\circ}$ 1, de 1969. preceitua em seu Artigo 175, parágrafo 4.": "Lei especial disporá sobre ₹ assistência à maternidade, à infância e à adolescência e sobre a educação de excepcionais". Este dispositivo: soma-se aos outros, tais como sobre saúde, educação, trabalho e direitos individuais, que visam as pessoas em geral.

Há muitos no Brasil, que estão organizando instituições para fazer faco às graves falhas sociais que estão colhendo a criança e os jovens em suas malhas. A sociedade de consumo tem efeito negativo sobre a mentalidade $\mathrm{em}$ formação. Enfermeiras e outras profissionais, mães modestas e muitos outros, em trabalho voluntário, estão ajudando menores. Como se viu no relatório da França, citado, compete à sociedade civil a ação. Não vamos esperar do Governo o que lhe é quase impossível fazer bem feito. O icampo é preferentemente da sociedade civil. Organizemos as Aldeias S.O.S. nossas, as comunidades integradas como a de: Santa Rosa de Lima Sergipe, da professora Waleska Paixão, e como a Associação Brasiliense Evangélica Assistencial, da Sra. Martha Rachel França. Imitemos centenas de organizações das Congregaçōes Religiosas. O problema do menor está sendo referido como o maior dos problemas sociais do país. Quanto à criança, a origem desse nome o diz: é para ser criada. Em amor, cresce em estatura, entendimento e graça.

Enfermeiros são peritos em utilizar conhecimentos de sociologia e psicologia, além das ciências biológicas; e em se associarem a outros profissionais no trabalho, principalmente junto a grupos da comunidade. Está aqui um dos campos mais interessantes, na sociedads civil, para os profissionais das ciências da saúde e das sociais: cuidar de fortalecer as famílias dos mais pobres e de instituir lares onde haja amor e que criem os meninos, hoje carentes, para serem os homens e as mulheres do fi!turo deste país.

\subsection{Futuro já delineado: um novo papel dos enfermeiros}

Há uma parcela de enfermeiros do país em serviços novos - é bom que se registre neste Ano Internacional da Criança - ocupando-se da assistência à população materno-infantil: são aquelas enfermeiras e enfermeiros que trabalham no Programa de Interiorização das Ações de Saúde e Saneamento, desdobrado em Programas Estaduais das 
DOURADO, H. G. - Aspectos da saúde da criança e enfermagem. Rev. Bras. Enf.; DF, $33: 9-21,1980$.

Secretarias de Saúde, com as quais a Fundação SESP atúa conjuntamente. Mas a criança também está ajudando os enfermeiros. Ao entrar em ação no papel novo, nos programas de assistência primária, poderá o enfermeiro descobrir que ele é essencial na assistência à saúde. Pode encontrar a razão de ser de sua profissão hoje.

\section{CONSIDERACOES GERAIS}

O menor no Brasil de hoje apresenta necessidades clamorosas para as quais gránde parte das esferas da cultura terá que planejar e desenvolver ação.

O setor das profissões é um dos mais importantes da cultura. Dentre as profissões, situa-se a de enfermagem.

Os enfermeiros e os demais do pessoal de enfermagem provaram valor no que têm feito neste país. Veja-se por exemplo, o complexo institucional de enfermagem. $O$ desafio é sempre maior quando a capacidade de percepção da realidade aumenta.

Por outro lado, falta de estudos sérios, hedonismo, efeitos da sociedade de consumo e várias outras condições podem estar impedindo os enfermeiros, técnicos de enfermagem e demais de enfermagem de entrarem nos caminhos estreitos que os podem levar a contribuir decisivamente no setor que é deles e não de outros, na sociedade.

As instituições sociais dos países, à medida que se tornam desenvolvidos, crescem em complexidade e interrelacionamento. Afortunadamente os planos de saúde do Brasil hoje, incluindo intrincados programas de interiorização das ações de saúde e saneamento, encontraram a formação e a experiência dos enfermeiros com certo progresso. Desse modo podem ser preparados para que participem desses programas em que $o$ papel do enfermeiro exige interesse genuíno na pessoa humana, capacidade, criatividade e real formação profissional e de administração e ensino.

No que diz respeito aos estabelecimentos de saúde, a julgar por recomendações dos Congressos Brasileiros de Enfermagem, os enfermeiros se têm manifestado com desejo de reajustar os serviços de enfermagem a seus fins; lutam com impedimentos, muitos dos quais são ligados à falta de poder decisório de grupos minoritários, tais como as mulheres na força de trabalho.

Tal como aconteceu em 1923 até 1961, para que se situasse e se efetivasse o ensino para graduar enfermeiros, também na década 1980 os enfermeiros terão que tornar mais significativos seus papéis próprios. Estes estarão surgindo da ação e interação diárias do trabalho e dos consensos obtidos com os colegas enfermeiros e com os demais profissionais de saúde, dentro de uma atmosfera profissional, - isto é, com as caracteristicas de responsabilidade e maturidade desses grupos.

Faltam algumas medidas as quais têm sido objeto de estudo e recomendação da Associação Brasileira de Enformagem: a) algumas estruturas, tais como o INAMPS e estabelecimentos de saúde não contam com órgãos de enfermagem na hierarquia adequada; b) são insuficientes os empregos do pessoal de enfermagem, em comparação com o trabalho a ser realizado no setor saúde, e são quase inexistentes os empregos para técnicas de enfermagem; c) são em número escasso os cursos de educação continuada para enfermeiros, técnicos de enfermagem e todo o pessoal do serviço de enformagem. Faltam providências legais e outras para que os atuais atendentes sejam elevados às categorias do pessoal de enfermagem, e para que se dificulte a entrada de mãode-obra não qualificada nos estabelecimentos de saúde para ações de enfermagem, propriamente dita. 
DOURADO, H. G. - Aspectos da saúde da criança e enfermagem. Rev. Bras. Ent.; DF, $33: 9-21,1980$.

Nos programas comunitários de extensão de cobertura e nos estabelecimentos hospitalares e para-hospitalares e serviços oficiais de saúde pública são de grande importância para a sociedade brasileira o que os enfermeiros fazem, não só enfermeiros como os demais da área.

Os enfermeiros e todos os cidadãos deste país que tenham sensibilidade para as necessidades sociais estão diante do problema da criança e do menor. Cuidar da criança e do menor na profissão e como membro da sociedade civil, desenvolvendo amor a quem depénde de amor.
O Brasil pode desenvolver nesta parte equatorial a meridional do globo uma civilização neo-latina e neo-afroamerindianista com instituições de justiça e fraternidade e oportunidade para todos. Foi muito significativo ouvir o representante da civilização da França, país do qual temos heranças profundas, ao ser inaugurada, em julho último, no Rio de Janeiro, a Casa da Cultura do Brasil: declarou ele, que deposita em nós a esperança de um novo tempo em que o Brasil, tudo leva a crer, será destacado entre os países para erguer a tocha simbólica das civilizações latinas com civismo e iguais oportunidades.

\section{BIBLIOGRAFIA}

1. BRASIL. F'undaçāo Instituto Brasileiro de Geografia e Estatística. Anuário Estatistico do Brasil, 1977 e 1978.

2. CASTRO, Ieda B. Conceito de Saúde predicativos e implicações. Rev. Bras Enf., DF; 31:275-280, 1978.

3. DOURADO, Adahilton. O excepciona] e as leis brasileiras. Conferência. Congresso da Associaçāo de Pais e Amigos dos Excepcionais (APAE) Florianópolis, 1979 (no prelo).

4. DOURADO, H. G. e COELho, C. P. BRASIL: Saúde da criança: aspectos da assistência le enfermagem. International Nursing Review; Genebra, 1979 (no prelo).
5. MATOS, Adalgisa V. Assistência Primaria de Saúde. Implicaçőes para a enfermagem. Rev. Bras. Enf., DF, 3-22, 1978.

6. - - - - A Enfermagem e o Sistema Nacional de Saúde. Anais do XXX Congresso Brasileiro de Enfermagem, DF, 1978.

7. ORGANIZACION PANAMIERICANA DE SALUD/OMS. Conferencia Intermacional sobre Atencion Primárla de la Salud. Educación Médica y Salud, Washington, D.C. Vol. 13, n.0 1 , 1979.

8. STRENGER, Irineu. Telemática: nov8 escola técnica. O Estado de Săo Paulo (jornal), São Paulo, 31-7-79. p. 21. 